Gynecologic and

Obstetric Investigation
Gynecol Obstet Invest 2019;84:166-173

DOI: $10.1159 / 000491084$
Received: February 22, 2018

Accepted after revision: June 18, 2018

Published online: October 12, 2018

\title{
Clinical Impact of a Restrictive Labor Induction Approval Process
}

\author{
Mary Catherine Tolcher ${ }^{\mathrm{a}}$ Alexis N. Hokenstad ${ }^{\mathrm{b}}$ Amy L. Weaver ${ }^{\mathrm{c}}$ \\ Michaela E. McGree ${ }^{c}$ Carl H. Rose ${ }^{b}$ Abimbola O. Famuyide ${ }^{b}$ Brian C. Brost $^{d}$ \\ ${ }^{a}$ Division of Maternal-Fetal Medicine, Baylor College of Medicine, Houston, TX, USA; ${ }^{b}$ Department of Obstetrics and \\ Gynecology, Mayo Clinic, Rochester, MN, USA; ' $D$ Department of Health Sciences Research, Division of Biomedical \\ Statistics and Informatics, Mayo Clinic, Rochester, MN, USA; dDivision of Maternal-Fetal Medicine, Wake Forest \\ School of Medicine, Winston Salem, NC, USA
}

\section{Keywords \\ Induction of labor · Elective delivery · Nonmedically indicated delivery $\cdot$ Cesarean delivery}

\begin{abstract}
Background/Aims: The aim of this study was to evaluate the impact of a restrictive labor induction approval process on induction and primary cesarean delivery rates. Methods: A retrospective cohort study was conducted at a tertiary care academic center from 2006 through 2012. The cohort of deliveries before (pre-intervention) and after (post-intervention) the process included term, singleton pregnancies with no contraindication to vaginal delivery. The primary outcome was induction of labor rates, subgrouped on the basis of whether it was medically or nonmedically indicated. Secondary outcomes included the primary cesarean rate and other maternal and neonatal outcomes. Results: Of 13,753 deliveries, 6,746 met study inclusion criteria. There was a significant decrease in induction rates comparing the pre- and post-intervention periods ( 21.0 vs. $18.5 \%, p=0.01$ ). Nonmedically indicated induction rates also decreased significantly ( 2.9 vs. $0.6 \%, p<0.001)$. No difference was observed in medically indicated induction (18.1 vs. $17.9 \%, p=0.84)$,
\end{abstract}

\section{KARGER}

() 2018 S. Karger AG, Basel

E-Mail karger@karger.com

www.karger.com/goi the primary cesarean rate $(14.4$ vs. $15.8 \%, p=0.12)$, or any of the measured neonatal outcomes $(p>0.05)$. Conclusions: Implementation of a labor induction approval process was associated with a significant reduction in overall and nonindicated induction rates but did not affect the primary cesarean rate or neonatal outcomes.

(c) 2018 S. Karger AG, Basel

\section{Introduction}

Induction of labor is a common obstetrical intervention with reported rates of up to $42.9 \%$ among nulliparous women and $31.8 \%$ among multiparous women [1]. Benefits of induction of labor include the ability to control the timing and location of delivery when the risks of pregnancy continuation outweigh the benefits (e.g., hypertensive disorders, diabetes, and fetal growth restriction). However, nonmedically indicated induction of labor results in prolonged hospitalization prior to delivery with resultant increase in resource utilization $[2,3]$.

This work was completed at Mayo Clinic, Rochester, MN, USA.
Mary Catherine Tolcher, MD, MSc

Department of Obstetrics and Gynecology

Baylor College of Medicine

6651 Main Street, 10th Floor, Houston, TX 77030 (USA)

E-Mail tolcher@bcm.edu 
Non-indicated delivery prior to 39 weeks of gestation has been associated with increased adverse neonatal outcomes $[4,5]$. Previous studies have proposed several strategies to reduce non-indicated deliveries prior to 39 weeks of gestation [6-8]. Clark et al. [6] showed that of 3 selected approaches, including physician education, peer review, and a "hard stop" hospital policy, the "hard stop" proved the most effective, resulting in both a decrease in non-indicated early-term delivery and term neonatal intensive care unit (NICU) admission. Two other studies have reported interventions to specifically decrease nonindicated inductions up to 41 weeks of gestation, but indications for induction and maternal and neonatal outcomes were not consistently reported $[9,10]$. Neither analyzed intervention effect on the primary cesarean rate, commonly considered the most significant risk of labor induction.

Our institution implemented a multidisciplinary, comprehensive induction review process to evaluate appropriate timing and indications for delivery based on national guidelines. While multiple studies have evaluated the effectiveness of different approaches to decrease non-indicated delivery [6-12], none have examined a comprehensive case review process of all inductions and the impact on primary cesarean delivery. The objective of the current study was to evaluate the effect of our induction approval process on indicated and non-indicated labor induction rates and other maternal and neonatal outcomes including the primary cesarean delivery rate.

\section{Materials and Methods}

All women with a singleton pregnancy in cephalic presentation delivering at term (37 weeks of gestation or greater) at Mayo Clinic Rochester from July 1, 2006 through May 31, 2012 were identified. The first 30 months preceding the induction approval process implementation were termed the pre-intervention period (July 1 , 2006 through December 31, 2008), the 12 months of 2009 the transition period, and the last 29 months the post-intervention period (January 1, 2010 through May 31, 2012). Exclusion criteria included preterm delivery ( $<37$ weeks of gestation), multiple gestations, fetal malpresentation, abnormal placentation, and prior cesarean or myomectomy. This manuscript is written in accordance with The Strengthening the Reporting of Observational Studies in Epidemiology statement: Guidelines for Reporting Observational Studies [13], and the study was approved by the Mayo Clinic Rochester Institutional Review Board.

In 2009, our institution implemented a preemptive, multidisciplinary induction approval process with the intention to restrict non-indicated induction of labor prior to 41 weeks of gestation. Our practice standards include avoiding non-indicated delivery prior to 41 weeks of gestation. For non-indicated inductions prior to 39 weeks of gestation, the labor and delivery scheduling nurse was em-

Induction Approval Process and Clinical Outcomes powered to enforce a "hard stop" by notifying the Obstetrics Division Chair. In cases of non-indicated delivery at or beyond 39 weeks, the primary provider was contacted to reschedule the induction. Practice protocols are consistent with national guidelines in terms of timing of delivery for specific fetal or maternal conditions [14]. American College of Obstetricians and Gynecologists criteria for confirmation of gestational age is emphasized [15].

The primary outcome of the study was the induction of labor rate. Secondary outcomes included the non-indicated induction rate, the primary cesarean rate, and maternal and neonatal clinical outcomes. Data on maternal demographics, gestational age at delivery, mode of delivery, neonatal birthweight, Apgar scores, and disposition were collected from the institution's obstetrics database, which is obtained via electronic medical review and manual entry by data technicians. Data on the maternal hospital length of stay was obtained from hospital administrative data. Finally, the review of hospital discharge International Classification of Diseases, 9th Revision codes was utilized to capture inductions, maternal comorbidities (hypertension and diabetes mellitus), and maternal outcomes including perineal lacerations, postpartum hemorrhage, chorioamnionitis, endomyometritis, wound infection, venous thromboembolism, and blood transfusion. Data on timing and indication for induction were collected retrospectively and manually from the electronic medical record by 2 physicians (M.C.T. and A.N.H.).

Inductions were categorized as medically indicated or nonmedically indicated based on a combination of recommendations from American College of Obstetricians and Gynecologists Committee Opinions and Practice Bulletins, considering both the indication and timing of delivery (online suppl. Appendix 1; for all online suppl. material, see www.karger.com/doi/10.1159/000491084). Where evidence or national recommendations were lacking, we used group consensus to categorize inductions. The expert consensus group consisted of the first author (obstetrician), 5 MaternalFetal Medicine faculty, and 3 Maternal-Fetal Medicine fellows. If more than 1 indication for induction was present, the primary indication was determined using a tiered hierarchy system (online suppl. Appendix 2). As we previously described [16], we considered inductions performed at or beyond 37 weeks of gestation that were preceded with a mature amniocentesis as medically indicated due to historic acceptance of this practice during the study period that predated the current wealth of evidence that neonatal morbidity is increased prior to 39 weeks of gestation $[5,17,18]$. For the duration of the study, we utilized standard clinical order sets for cervical ripening and oxytocin induction, including Foley catheter balloon or vaginal misoprostol 25 micrograms for cervical ripening with an unfavorable Bishop score (generally less than 6). The choice of cervical ripening agent and timing of rupture of membranes is based on patient and provider preference.

An interrupted time series design was used for data analysis; calendar month served as the unit of analysis, and the following 2 outcome measures were evaluated separately: monthly induction rate and monthly cesarean rate. For each outcome, the following regression model was fit, $\mathrm{E}(\mathrm{Y})=\beta 0+\beta 1$ "time" $+\beta 2$ "intervention" $+\beta 3$ "time after intervention" + error, where "time" denotes the number of months sequentially from the first month in the pre-intervention period, "intervention" is an indicator variable denoting the 2 time periods (pre- and post-intervention), "time after intervention" denotes the number of months after the intervention, $\beta 0$ represents a constant term for the level of the outcome at 
Table 1. Baseline characteristics for delivery cohort $(n=6,746)$

\begin{tabular}{|c|c|c|c|}
\hline Characteristic & $\begin{array}{l}\text { Pre-intervention } \\
(n=3,508)\end{array}$ & $\begin{array}{l}\text { Post-intervention } \\
(n=3,238)\end{array}$ & $p$ value \\
\hline Age, years, mean (SD) & $28.9(5.3)$ & $29.3(4.9)$ & $<0.001$ \\
\hline Race, $n(\%)$ & & & 0.03 \\
\hline White & $2,833(80.8)$ & $2,672(82.5)$ & \\
\hline American Indian/Alaskan & $6(0.2)$ & $4(0.1)$ & \\
\hline Black & $160(4.6)$ & $168(5.2)$ & \\
\hline Hawaiian/Pacific Islander & $6(0.2)$ & $1(0.03)$ & \\
\hline Asian & $173(4.9)$ & $149(4.6)$ & \\
\hline Other/unknown & $330(9.4)$ & $244(7.5)$ & \\
\hline Hispanic, $n(\%)$ & $160(4.6)$ & $144(4.4)$ & 0.82 \\
\hline Nulliparous, $n(\%)$ & $1,548(44.1)$ & $1,337(41.3)$ & 0.02 \\
\hline Pre-pregnancy weight ${ }^{\mathrm{a}}, \mathrm{kg}$, mean (SD) & $70.3(16.9)$ & $71.2(16.9)$ & 0.10 \\
\hline Hypertension, $n(\%)$ & $300(8.6)$ & $335(10.3)$ & 0.01 \\
\hline Diabetes, $n(\%)$ & $751(21.4)$ & $753(23.3)$ & 0.07 \\
\hline
\end{tabular}

the start of the pre-intervention period, $\beta 1$ represents the change in outcome per month (i.e., linear trend) during the pre-intervention period, $\beta 2$ represents the change in the level of the outcome during the post-intervention period, and $\beta 3$ represents the change in the linear trend during the post-intervention period, compared to the trend during the pre-intervention period. The data for the transition period were not included in the analysis. The regression models were fit using SAS Proc Autoreg (version 9.2, SAS Institute, Inc., Cary, NC, USA). Although the outcomes are counts per month, the "mean equals variance" assumption for a Poisson distribution was not met; therefore, Poisson regression models were not fit. The Durbin-Watson statistic was evaluated for evidence of serial autocorrelation. Since the Durbin-Watson statistic indicated a lack of autocorrelation, the models were not corrected for autocorrelation.

Baseline characteristics are descriptively summarized using mean and SD for continuous variables that have a normal Gaussian distribution and median and interquartile range for continuous variables with a skewed distribution. Frequencies and percentages were used to summarize categorical baseline characteristics. Baseline characteristics and outcomes were compared using the 2 -sample $t$ test or Wilcoxon rank-sum test for continuous variables and chi-square or Fisher's exact test for categorical variables, as appropriate, with a $p$ value of $<0.05$ considered to represent statistical significance.

\section{Results}

From July 1, 2006 through May 31, 2012, 13,753 deliveries were performed at our institution; of those, 6,746 met study inclusion criteria and were considered candidates for vaginal delivery: 3,508 pre-intervention and 3,238 post-intervention (Table 1, Fig. 1). Baseline characteristics were clinically similar between the 2 groups, de-

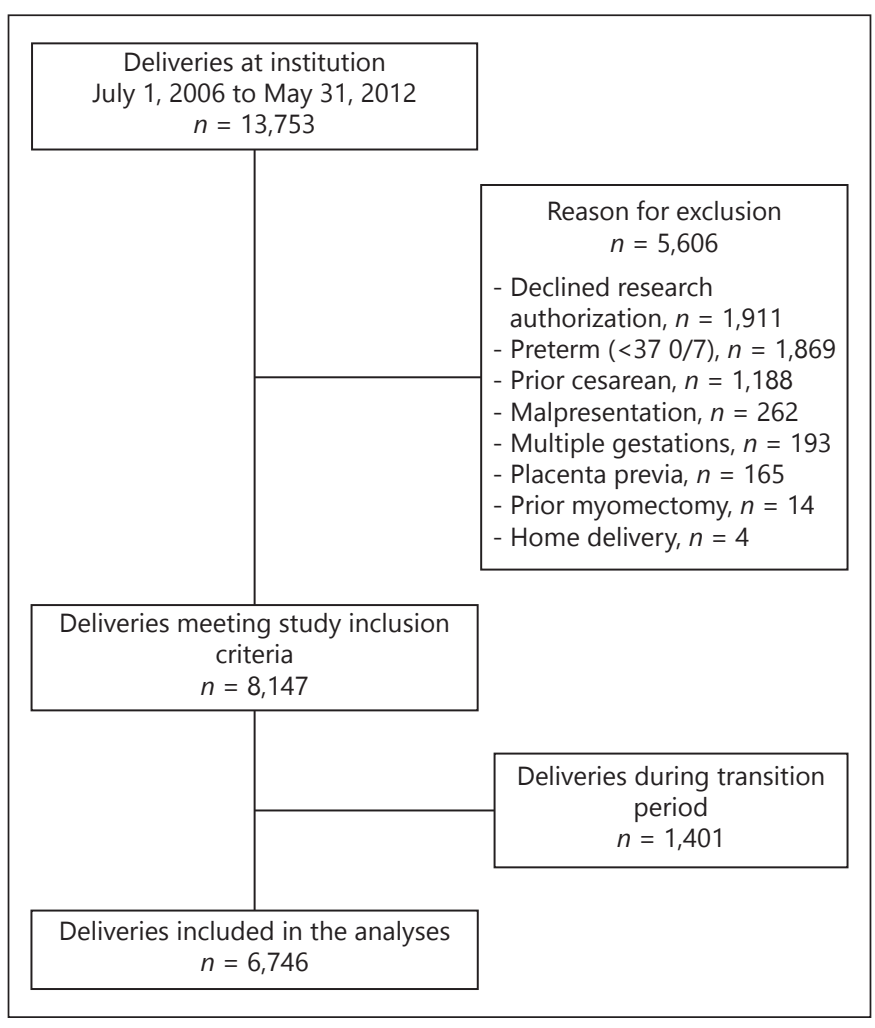

Fig. 1. Flow diagram of the study cohort selection.

spite statistically significant differences that were detected, given the large sample size.

There were 1,337 total inductions (19.8\%): 737 preintervention and 600 post-intervention. Most inductions were medically indicated $(91 \%)$. The rate of labor induc- 
Table 2. Maternal and neonatal outcomes in the pre- and post-intervention periods $(n=6,746)$

\begin{tabular}{|c|c|c|c|}
\hline Characteristic & $\begin{array}{l}\text { Pre-intervention } \\
(n=3,508)\end{array}$ & $\begin{array}{l}\text { Post-intervention } \\
(n=3,238)\end{array}$ & $p$ value $^{\mathrm{a}}$ \\
\hline Induction, $n(\%)$ & $737(21.0)$ & $600(18.5)$ & 0.01 \\
\hline Medically indicated induction, $n(\%)$ & $636(18.1)$ & $581(17.9)$ & 0.84 \\
\hline Nonmedically indicated induction, $n(\%)$ & $101(2.9)$ & $19(0.6)$ & $<0.001$ \\
\hline Delivery type, $n(\%)$ & & & 0.10 \\
\hline Cesarean delivery & $505(14.4)$ & $510(15.8)$ & \\
\hline Forceps-assisted vaginal delivery & $138(3.9)$ & $98(3.0)$ & \\
\hline Vacuum-assisted vaginal delivery & $90(2.6)$ & $78(2.4)$ & \\
\hline Spontaneous vaginal delivery & $2,775(79.1)$ & $2,552(78.8)$ & \\
\hline Gestational age at delivery, $n(\%)$ & & & 0.06 \\
\hline $37-38$ & $889(25.3)$ & $741(22.9)$ & \\
\hline $39-41$ & $2,611(74.4)$ & $2,491(76.9)$ & \\
\hline $42+$ & $8(0.2)$ & $6(0.2)$ & \\
\hline 3 rd or 4 th degree laceration, $n(\%)$ & $79(2.3)$ & $57(1.8)$ & 0.18 \\
\hline Birthweight, g, median (IQR) & $3,485(3,175-3,800)$ & $3,480(3,190-3,800)$ & 0.90 \\
\hline 5-Min APGAR score $<7, n(\%)$ & $50(1.4)$ & $57(1.8)$ & 0.27 \\
\hline NICU admission, $n(\%)$ & $64(1.8)$ & $66(2.0)$ & 0.52 \\
\hline Stillbirth $^{\mathrm{b}}, n(\%)$ & $2(0.1)$ & $5(0.2)$ & 0.27 \\
\hline Neonatal death, $n(\%)$ & $3(0.1)$ & $0(0.0)$ & 0.25 \\
\hline
\end{tabular}

tion pre-intervention was higher than that of post-intervention ( 21.0 vs. $18.5 \%, p=0.01$; Table 2 , Fig. 2 ). There was a nonsignificant decrease in the induction rate during the pre-intervention period $(p=0.29$ for testing whether the slope is different from zero). By the start of the postintervention period, the estimated induction rate had decreased by 4.1 deliveries per month $(p=0.047)$. During the post-intervention period, there was a significant change in the month-to-month trend compared to the pre-intervention period $(p=0.024)$. There was no difference in the rate of indicated inductions (18.1 vs. $17.9 \%$, $p=0.84$; Fig. 3), but non-indicated induction rates were significantly reduced in the post-intervention period (2.9 vs. $0.6 \%, p<0.001$; Fig. 4 ).

There was no difference in the primary cesarean rate between the pre- and post-intervention time periods ( 14.4 vs. $15.8 \%, p=0.12$; Fig. 5). Over the course of the 30 -month pre-intervention period, there was no significant change in the primary cesarean rate $(p=0.24)$. However, by the start of the post-intervention period, the estimated cesarean rate had increased by 3.1 deliveries per month $(p=0.10)$. There was a decrease in deliveries less than 39 weeks of gestation from pre- to post-intervention time periods ( 25.3 vs. $22.9 \%, p=0.02$ ).

Induction Approval Process and Clinical Outcomes
There were no significant differences observed in any of the measured neonatal outcomes including median birthweight, 5-min Apgar score $<7$, or NICU admission (Table 2). Although an increase in the stillbirth rate from $2(0.1 \%)$ during the pre-intervention period to $5(0.2 \%)$ during the post-intervention period was noted, this difference was not statistically significant $(p=0.27)$. There were 3 neonatal deaths in the study. All occurred in the pre-intervention period and were neonates with aneuploidy or major fetal anomalies.

Analysis of secondary maternal outcomes revealed a significant decrease in both wound infection $(p<0.001)$ and venous thromboembolism $(p=0.04)$ in the post-intervention period (Table 3 ). There were no differences in rates of postpartum hemorrhage, chorioamnionitis, endomyometritis, or blood transfusion.

\section{Discussion}

Implementation of a preemptive induction approval process at our institution was associated with a decrease in both overall and non-indicated labor induction rates, as well as reductions in wound infection and venous 
Fig. 2. Time series of induction rates by month (number of inductions per $100 \mathrm{de}$ liveries per month). Lines indicate boundaries of transition period between pre- and post-intervention.
Fig. 3. Time series of medically indicated induction rates by month (number of medically indicated inductions per 100 deliveries per month). Lines indicate boundaries of transition period between pre- and postintervention.
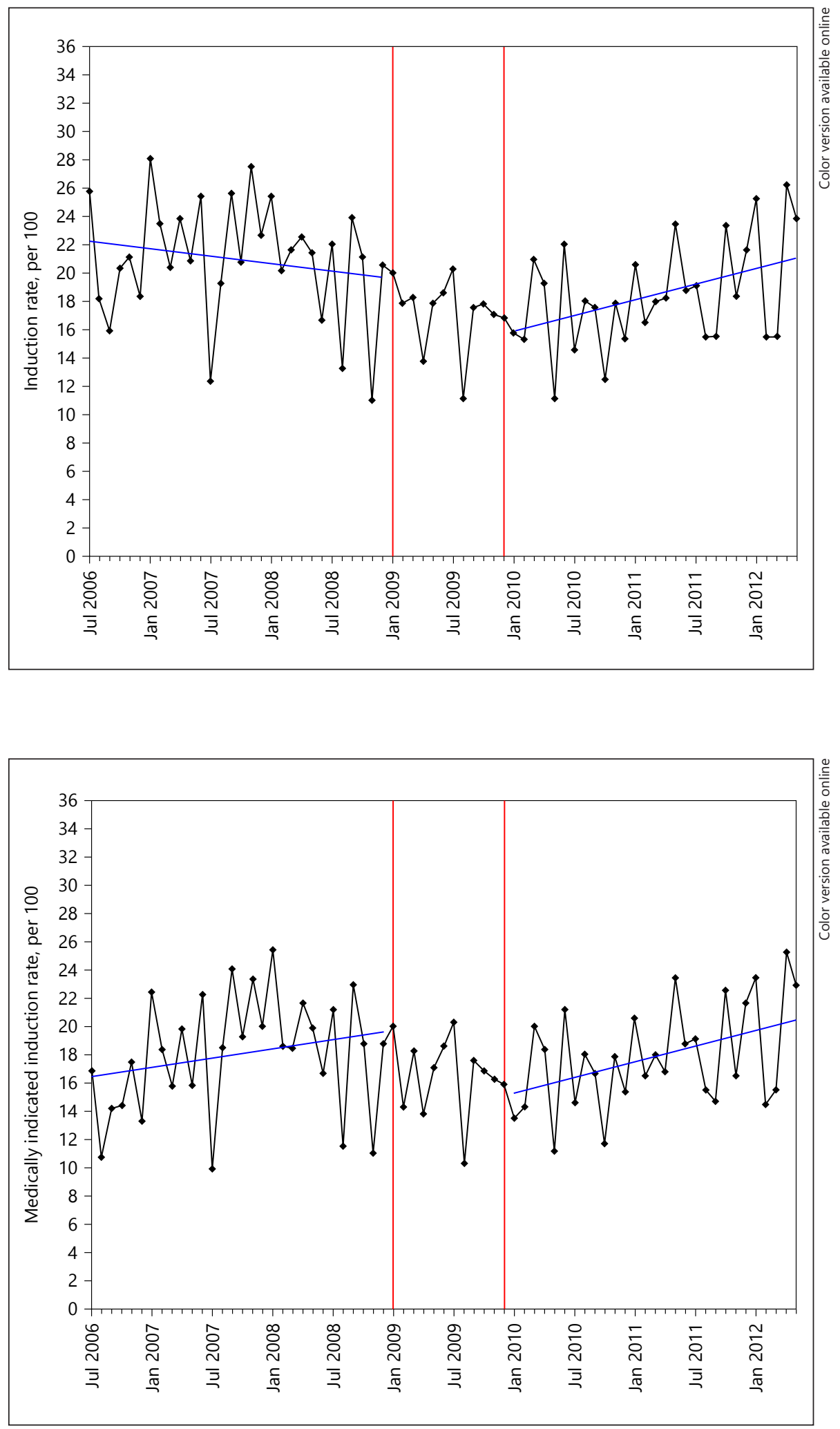
Fig. 4. Time series of nonmedically indicated induction rates by month number of nonmedically indicated inductions per 100 deliveries per month). Lines indicate boundaries of transition period between pre- and post-intervention.
Fig. 5. Time series of primary cesarean delivery rates by month (number of cesarean deliveries per 100 deliveries per month). Lines indicate boundaries of transition period between pre- and post-intervention.
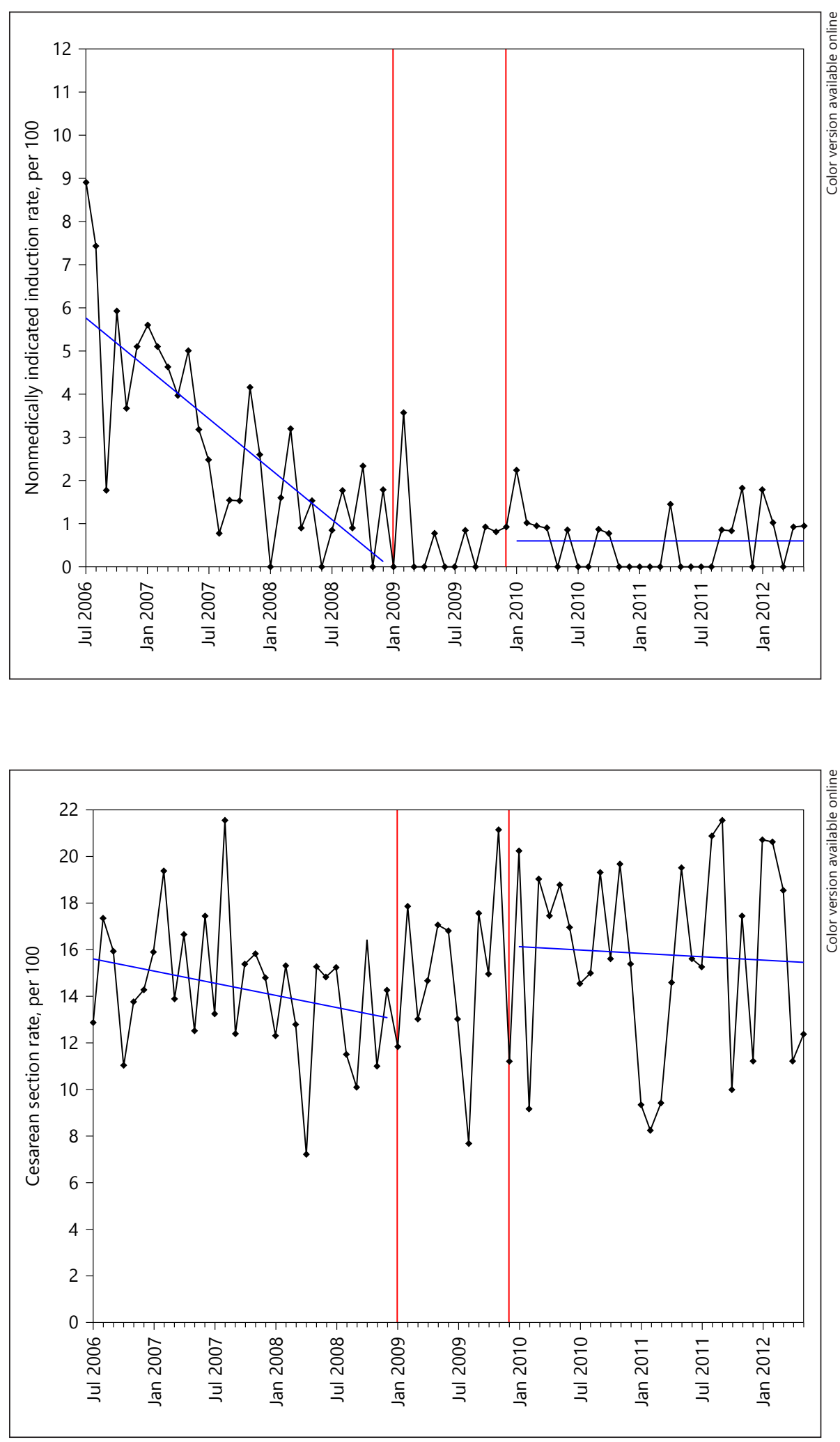
Table 3. Maternal postpartum outcomes (from delivery up to 6 weeks postpartum) in the pre- and post-intervention periods $(n=6,746)$

\begin{tabular}{lllc}
\hline Characteristic & $\begin{array}{l}\text { Pre-intervention } \\
(n=3,508)\end{array}$ & $\begin{array}{l}\text { Post-intervention } \\
(n=3,238)\end{array}$ & $p$ value $^{\mathrm{a}}$ \\
\hline $\begin{array}{l}\text { Postpartum } \\
\quad \text { hemorrhage }\end{array}$ & $142(4.1)$ & $146(4.5)$ & 0.35 \\
$\begin{array}{l}\text { Chorioamnionitis } \\
\text { Endomyometritis }\end{array}$ & $31(0.9)$ & $32(1.0)$ & 0.66 \\
Wound infection & $81(2.3)$ & $26(0.8)$ & 0.88 \\
VTE/DVT/PE & $15(0.4)$ & $36(1.1)$ & $<0.001$ \\
Transfusion & $22(0.6)$ & $5(0.2)$ & 0.04 \\
\end{tabular}

All data presented as $n(\%)$.

${ }^{a}$ Chi-square $p$ value.

VTE/DVT/PE, venous thromboembolism/deep vein thrombosis/pulmonary embolism.

thromboembolism. No differences were observed in indicated induction rate, the primary cesarean rate, maternal length of stay, postpartum hemorrhage, chorioamnionitis, endomyometritis, or NICU admission. We found a nonsignificant increase in stillbirth rates between the pre- and post-intervention periods. However, our study was underpowered for this outcome. Further, since all post-intervention stillbirths occurred between 37 and 39 weeks of gestation, we cannot attribute them to a restrictive induction policy between 39 and 41 weeks of gestation.

The decreasing trend in induction rates pre-intervention appears to be driven by a decrease in non-indicated induction, and our practice could have been influenced by increasing national interest in this topic prior to the implementation of our review process. However, after the implementation, there was a consistent and low level of non-indicated induction. We hypothesize that consistent preoperative administration of antibiotic prophylaxis and utilization of universal lower extremity sequential compression devices for cesarean delivery more likely explain the reduction in wound infection and venous thromboembolism rates, respectively, rather than our intervention.

Our institution chose to limit non-indicated inductions in order to standardize practice and limit resource utilization in our tertiary care referral center. Importantly, our findings do not support the use of restrictive induction of labor for pregnancies at or beyond 39 weeks of gestation for the purpose of improving the primary cesarean rate or other maternal or neonatal outcomes, which is in agreement with published population based studies [19]. The results of our study support contemporary evidence that induction of labor may decrease cesarean delivery rates when induction is compared to expectant management rather than spontaneous labor $[20,21]$.

Several limitations of the present study are important to consider. Inherent to the observational and retrospective design, we were unable to account for all patient and practice variables over the study period. Also, we did not have a means to effectively control for accuracy of hospital discharge coding, and it is conceivable that some inductions and outcomes were not captured. Additionally, though 2 authors utilized a standardized approach to categorize induction indications and whether medically indicated or not, this would ideally be done prospectively. Strengths of our study include the large cohort over a relatively short period of time (6 years), manual data abstraction for induction indication, and the utilization of an interrupted time series design - a quasi-experimental analysis including pre-intervention trends that better establishes the absence of other factors that could explain the observed changed.

We demonstrated a significant decrease in non-indicated induction rates after implementing a restrictive induction approval process. However, there was no demonstrated effect on primary cesarean rates or other adverse clinical outcomes. The lack of demonstrable impact of our restrictive induction policy on outcomes other than induction rates themselves suggests that restricting induction of labor at or beyond 39 weeks of gestation does not represent an effective strategy for reducing primary cesarean delivery. However, liberal non-indicated induction may increase resource utilization.

\section{Acknowledgments}

This publication was made possible by the Center for Translational Science Activities Grant Number UL1 TR000135 from the National Center for Advancing Translational Sciences (NCATS), a component of the National Institutes of Health (NIH). Its contents are solely the responsibility of the authors and do not necessarily represent the official view of the NIH. I also thank Drs. Wendy White, Norman Davies, Kristi Borowski, Arij Faksh, Charisse Trinidad, and Elizabeth Codsi for their participation in the expert consensus group.

\section{Disclosure Statement}

The authors declare that they have no conflicts of interest to disclose. 


\section{References}

1 Laughon SK, Zhang J, Grewal J, Sundaram R, Beaver J, Reddy UM: Induction of labor in a contemporary obstetric cohort. Am J Obstet Gynecol 2012;206:486.e481-e489.

2 Osmundson S, Ou-Yang RJ, Grobman WA: Elective induction compared with expectant management in nulliparous women with an unfavorable cervix. Obstet Gynecol 2011;117: 583-587.

3 Osmundson SS, Ou-Yang RJ, Grobman WA: Elective induction compared with expectant management in nulliparous women with a favorable cervix. Obstet Gynecol 2010;116:601605.

4 Hibbard JU, Wilkins I, Sun L, Gregory K, Haberman S, Hoffman M, Kominiarek MA, Reddy U, Bailit J, Branch DW, et al: Respiratory morbidity in late preterm births. JAMA 2010;304:419-425.

5 Tita AT, Landon MB, Spong CY, Lai Y, Leveno KJ, Varner MW, Moawad AH, Caritis SN, Meis PJ, Wapner RJ, et al: Timing of elective repeat cesarean delivery at term and neonatal outcomes. N Engl J Med 2009;360:111-120.

6 Clark SL, Frye DR, Meyers JA, Belfort MA, Dildy GA, Kofford S, Englebright J, Perlin JA: Reduction in elective delivery at $<39$ weeks of gestation: comparative effectiveness of 3 approaches to change and the impact on neonatal intensive care admission and stillbirth. Am J Obstet Gynecol 2010;203:449.e441-e446.

7 Oshiro BT, Henry E, Wilson J, Branch DW, Varner MW: Decreasing elective deliveries before 39 weeks of gestation in an integrated health care system. Obstet Gynecol 2009;113: 804-811.
8 Donovan EF, Lannon C, Bailit J, Rose B, Iams JD, Byczkowski T: A statewide initiative to reduce inappropriate scheduled births at 36(0/7)-38(6/7) weeks' gestation. Am J Obstet Gynecol 2010;202:243.e241-e248.

9 Harris S, Buchinski B, Grzybowski S, Janssen P, Mitchell GW, Farquharson D: Induction of labour: a continuous quality improvement and peer review program to improve the quality of care. CMAJ 2000;163:1163-1166.

10 Reisner DP, Wallin TK, Zingheim RW, Luthy DA: Reduction of elective inductions in a large community hospital. Am J Obstet Gynecol 2009;200:674.e671-e677.

11 Ehrenthal DB, Hoffman MK, Jiang X, Ostrum G: Neonatal outcomes after implementation of guidelines limiting elective delivery before 39 weeks of gestation. Obstet Gynecol 2011; 118:1047-1055

12 Oshiro BT, Kowalewski L, Sappenfield W, Alter CC, Bettegowda VR, Russell R, Curran J, Reeves L, Kacica M, Andino N, et al: A multistate quality improvement program to decrease elective deliveries before 39 weeks of gestation. Obstet Gynecol 2013;121:1025-1031.

13 von Elm E, Altman DG, Egger M, Pocock SJ, Gotzsche PC, Vandenbroucke JP: The Strengthening the Reporting of Observational Studies in Epidemiology (STROBE) statement: guidelines for reporting observational studies. Lancet 2007;370:1453-1457.

14 American College of Obstetricians and Gynecologists: ACOG Committee Opinion No. 560: medically indicated late-preterm and early-term deliveries. Obstet Gynecol 2013; 121:908-910.
15 ACOG Committee on Practice Bulletins Obstetrics: ACOG practice bulletin no. 107: induction of labor. Obstet Gynecol 2009; 114(2 pt 1):386-397.

16 Tolcher MC, Holbert MR, Weaver AL, McGree ME, Olson JE, El-Nashar SA, Famuyide AO, Brost BC: Predicting cesarean delivery after induction of labor among nulliparous women at term. Obstet Gynecol 2015;126: 1059-1068.

17 Clark SL, Miller DD, Belfort MA, Dildy GA, Frye DK, Meyers JA: Neonatal and maternal outcomes associated with elective term delivery. Am J Obstet Gynecol 2009;200:156.e151e154.

18 Spong CY, Mercer BM, D'Alton M, Kilpatrick S, Blackwell S, Saade G: Timing of indicated late-preterm and early-term birth. Obstet Gynecol 2011;118(2 pt 1):323-333.

19 Stock SJ, Ferguson E, Duffy A, Ford I, Chalmers J, Norman JE: Outcomes of elective induction of labour compared with expectant management: population based study. BMJ 2012; 344:e2838.

20 Cheng YW, Kaimal AJ, Snowden JM, Nicholson JM, Caughey AB: Induction of labor compared to expectant management in low-risk women and associated perinatal outcomes. Am J Obstet Gynecol 2012;207:502.e501e508.

21 Darney BG, Snowden JM, Cheng YW, Jacob L, Nicholson JM, Kaimal A, Dublin S, Getahun $D$, Caughey AB: Elective induction of labor at term compared with expectant management: maternal and neonatal outcomes. Obstet Gynecol 2013;122:761-769. 